\title{
Characteristics of pediatric pulmonary artery hypertension due to congenital porto-systemic shunt
}

\author{
Hiroshi Ono ${ }^{1}$, Taiyu Hayashi ${ }^{1}$, Takahiro Shindo ${ }^{1}$, Yasushi Misaki ${ }^{1}$, Mureo Kasahara ${ }^{1}$, \\ Shunsuke Nosaka ${ }^{1}$, and Hitoshi Kato ${ }^{1}$ \\ ${ }^{1}$ National Center for Child Health and Development
}

June 22, 2020

\begin{abstract}
Background: Congenital porto-systemic shunt (CPSS) is a rare condition that can cause pulmonary artery hypertension (PAH). Methods: We reviewed six patients who received treatment in our institution between 2011 and 2019. Results: Median age at diagnosis of CPSS was 2.5 months ( 0 to 9 years) and that of PAH was 5.6 years (0 to 7.1 years). All patients underwent intervention for CPSS. The median duration between diagnosis of CPSS and intervention for CPSS was 2.5 months $(2$ months to 8 years) and between diagnosis of PAH and intervention for CPSS was 2.5 months ( 1 month to 6 years). All patients received combination PAH-specific therapy, three drugs in three cases and two drugs in three cases. Only one infant who underwent intervention for CPSS at 3 months old discontinued pulmonary vasodilator after intervention, but all other patients continued taking it; three patients needed to boost the therapy. Conclusion: When treatment for CPSS is delayed, pulmonary arterial pressure does not decrease only by ligation of the shunt vessel, and PAH-specific therapy cannot be discontinued.
\end{abstract}

\section{Hosted file}

PAH for CEPS (6 cases)(2020.6.20).doc available at https://authorea.com/users/335833/ articles/461628-characteristics-of-pediatric-pulmonary-artery-hypertension-due-tocongenital-porto-systemic-shunt

\section{Hosted file}

Table (PAH due to CPSS).doc available at https://authorea.com/users/335833/articles/461628characteristics-of-pediatric-pulmonary-artery-hypertension-due-to-congenital-portosystemic-shunt 


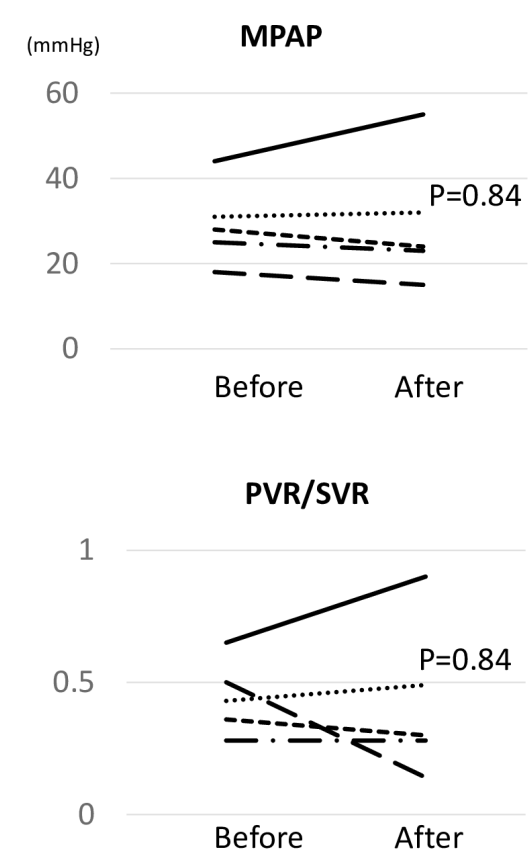

Figure 1
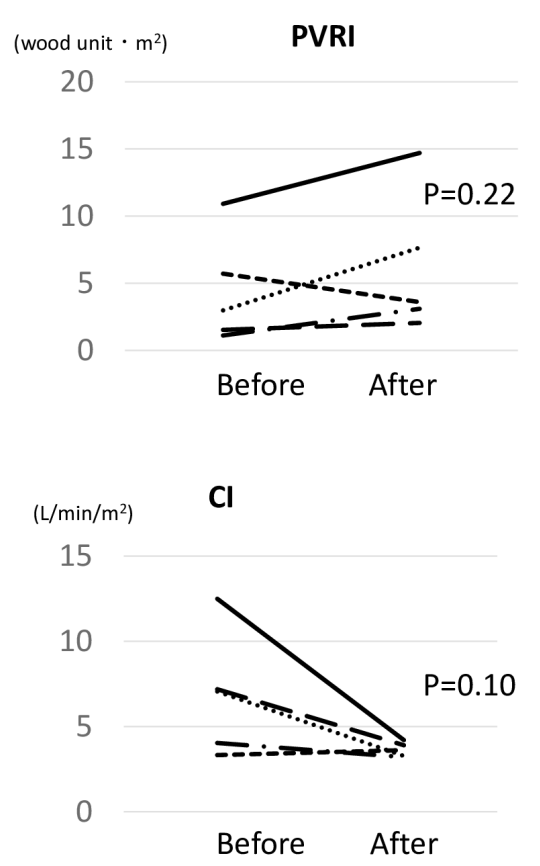

$(n=5)$ 